\title{
As percepções dos professores sobre o ensino a distância: uma reflexão sobre as teorias pedagógicas e a EaD
}

\author{
Adriana Torres Guedes \\ Faculdades Integradas de Taquara - FACCAT; adriguedes@ faccat.br \\ Querte Teresinha Conzi Mehlecke \\ Faculdades Integradas de Taquara -FACCAT; querte@ faccat.br \\ Janete Sander Costa \\ Faculdades Integradas de Taquara - FACCAT; jsander@faccat.br
}

Resumo: O presente estudo relata aspectos de uma pesquisa realizada pelo grupo de alunos do Curso de Capacitação Pedagógica em Educação a Distância, realizado no Núcleo de Educação a Distância - NEO, FACCAT, RS, em maio de 2008. Foram entrevistados professores em serviço, dos segmentos de ensino fundamental, médio e superior, quanto à sua percepção sobre as diferenças existentes entre a modalidade de ensino presencial e ensino a distância. O tratamento dos dados buscou identificar questionamentos predominantes dos docentes sobre a modalidade a distância e o papel do professor e da metodologia que adota para que essa atividade pedagógica atinja uma eficácia e uma qualidade reconhecida pelos próprios docentes.

Palavras-chaves: teorias pedagógicas, metodologia, educação a distância, percepção dos educadores.

Abstract: This is an exploratory study that presents aspects of a research carried out with a group of students of the Distance Learning Pedagogical Qualification course, offered by the Online Education Nucleous, at FACCAT, RS, in May, 2008. In service teachers from the Elementary, High School, and Undergraduate educational systems were interviewed on their perception about the differences they find between the in presence and distance learning teaching modes. Data analysis tryed to show teacher's predominant inquiries on the distance learning modality, the educator's role and their adopted methodology applied to the pedagogical activity toward an eficiency and quality recognised by the teachers themselves.

Keywords: pedagogical theories, methodology, distance learning, educator's perception.

\section{Perspectivas Teóricas: Ensinar e Aprender}

Existe no seio de cada teoria educacional uma concepção a respeito do que define o papel que o professor deve desempenhar para que ocorra o processo de aprendizagem do aluno. Segundo a abordagem de Greeno, Collins e Resnick (1996) citados por Filatro (2009, pp.96-98), o processo de ensino e aprendizagem pode adquirir distintos significados de acordo com o paradigma teórico predominante, sendo assim, um modo possível de categorizar as teorias pedagógicas é organizá-las sob três grandes perspectivas. Essas três perspectivas são a perspectiva associacionista, a cognitiva e a situada.

A perspectiva associacionista enfatiza a aprendizagem concebida como mudanças comportamentais observáveis resultantes de respostas a estímulos externos. Ensinar consiste, sob este ponto de vista, organizar atividades com complexidade progressiva estrategicamente para a assunção de determinadas habilidades. Também se enfatiza o percurso individual de cada pessoa para alcançar os objetivos propostos e a 
necessidade de mensurar resultados e garantir o feedback através dos métodos avaliativos. São autores representativos do associacionismo Skinner, Watson e Gagné.

O paradigma cognitivista preocupa-se com os processos internos de percepção, representação e construção de conhecimento. Destacam-se os estudos de Piaget sobre a formação das estruturas mentais e as implicações que as novas informações emergentes da interação do sujeito com o objeto de conhecimento (mundo externo) exercem sobre elas. Nesse processo de contato com as novas informações ocorre o desequilíbrio dessas estruturas mentais já existentes, o que leva a uma reorganização e ao surgimento de novas estruturas mentais como resultantes do processo de aprendizagem, caracterizando os movimentos de assimilação, adaptação e acomodação que atuam no desenvolvimento cognitivo.

Ainda sob essa perspectiva cognitiva, há autores como Dewey, que defendia a necessidade de a educação apoiar-se na reflexão sobre a experiência de vida do aluno, e Bruner, que entendia a aprendizagem como construção de significado frente às experiências que permitem ao aluno fazer descobertas e ir além da informação. Uma concepção cognitivista que se distingue desses enfoques mais detidos no processo cognitivo do ponto de vista individual é a abordagem sócio-histórica da aprendizagem proposta por Vigotsky, que compreende o aprender como resultante das interações e situações de cooperação social. Dessas experiências que desafiam e exigem a organização colaborativa dos sujeitos do aprender para a execução de tarefas que geram a formação de distintas habilidades, inclusive as sociais, resultam os processos superiores do pensamento.

Os pressupostos da perspectiva situada também sustentam a importância do contexto social e cultural como determinante da aprendizagem e avança em direção à idéia de que a situação através da qual o aluno constrói conhecimento precisa ser o mais próxima possível da realidade dele, na qual ele será capaz de aplicar o que está aprendendo. Dessa relação com esse contexto social e de ordem se traça também a identidade do aluno como agente de sua comunidade e de seu meio.

Através da leitura dessas três perspectivas teóricas do fazer pedagógico pode-se constatar que o olhar sobre o ensinar e o aprender na atualidade move-se, sem deixar de valorizar as muitas contribuições de cada uma dessas perspectivas teóricas, em direção à criação de contextos de aprendizagem autênticos, o que ressalta o caráter social e colaborativo do aprender e a relação do papel do professor com um ensinar que esteja em consonância com esses fundamentos. Suas competências pedagógicas visam a promoção da participação dos alunos em atividades desafiadoras, que lhes despertem a autonomia e o espírito de investigação, tenham aplicabilidade ao contexto social e cultural em que vivem e que reforcem suas habilidades sociais e o desenvolvimento de identidade gerando um conhecimento compartilhado.

\section{Tecnologias Educacionais}

Nas discussões atuais sobre teorias educacionais tem-se o impacto das Tecnologias de Informação e Comunicação - TIC na educação como protagonista de grande parte dos debates que se têm realizado em prol de maior qualidade do ensino.

Os estudos do uso das novas tecnologias na educação, de um modo geral, demonstram que reside nas mudanças metodológicas e na emergência de uma nova prática docente boa parte da inovação de que carece o ensino hoje, já que o acesso aos recursos tecnológicos não garante avanços de qualidade na aprendizagem, a menos que esteja acompanhado de uma transformação dos próprios professores, de sua capacidade de experimentação frente a novos modos de conhecer, de aprender e de ensinar. 
A esse respeito, Oliveira (2003) diz que:

"No contexto das propostas pedagógicas e opções metodológicas emergentes, o uso das novas/novíssimas tecnologias da informação e da comunicação não garante a inovação educacional, pois o salto transformador depende da forma como os instrumentos tecnológicos são utilizados para superar a reprodução do conhecimento e contribuir com a produção de um saber significativo e contextualizado, para o desenvolvimento de competências, habilidades e atitudes imprescindiveis à construção de uma vida e de um mundo melhores para todos, (re)significando o reconhecimento científico que 'ensina a viver e traduz-se num saber prático". (p.32)

Há um giro, portanto, que se faz necessário, uma vez que não se trata de utilizar os novos recursos tecnológicos para realizar uma transposição de tarefas e construções de conhecimento à moda antiga. Se a prática do professor sofre uma mudança consistente com esse impacto tecnológico, sua percepção frente ao que vem a ser a construção de conhecimento e à natureza de sua contribuição nesse processo consolidam essa sua transição paradigmática rumo a uma nova concepção da educação. Digamos que os docentes, ao vivenciarem de fato esse impacto das novas tecnologias, orientados por uma formação adequada rumo a essas transformações de sua prática pedagógica, serão capazes de problematizar sistematicamente as formas de conhecer constituídas.

Neste sentido, Kastrup (2000), salienta que:

"Os dispositivos técnicos funcionam, para a cognição, como instrumentos para a solução de problemas, mas também, sobretudo, produzem a invenção de problemas. A invenção de problemas revela-se quando dificuldades e resistências são enfrentadas pela introdução de novas tecnologias cognitivas no cotidiano dos usuários. Entretanto, em seu sentido mais forte e importante, a invenção de problemas corresponde à capacidade dos dispositivos técnicos de atuarem no processo de virtualização da inteligência e na alteração das formas de conhecer constituídas."(KASTRUP, p. 38 In: PELLANDA)

As investigações sobre o impacto da tecnologia podem assim ser divididas em dois grupos: o primeiro considera que as inovações tecnológicas e os recursos delas derivados são instrumentos que objetivam amplificar as capacidades humanas para resolver problemas, levar o homem a superar limites. Enquanto o segundo grupo entende que a tecnologia alarga a potência criadora do homem, em resposta a isso o ser humano sofre modificações, é afetado pela tecnologia de maneira que surgem nele novas necessidades, novos questionamentos que fazer vir à tona novas formas de conhecer e pensar, novos modos de perceber a realidade e pode-se dizer também: novas formas de ensinar.

Sendo assim, as novas tecnologias na educação não geram novas soluções para antigos desafios, mas, sobretudo, inserem no campo de atuação do professor fazeres diferentes, criações de propostas pedagógicas como resultados que não podem ser antecipados, que vão atualizando-se nas relações novas que se configuram entre o homem e os dispositivos tecnológicos, ou seja, trata-se da emergência de tecnologias intelectuais.

A respeito dessa questão, Maraschin e Axt (2005) propõem a noção de acoplamento tecnológico, o qual é entendido como um processo de apropriação que se concretiza a partir das práticas, que ocorre na medida em que no encontro dos seres humanos com a tecnologia exista aprendizado de fato, de modo a renovar-se e se modificar a maneira de pensar e de conhecer. Se uma determinada tecnologia tem surgimento, em conseqüência disto tem-se também inovação, ampliação de 
determinados processos de cognição em função dos quais haverá instituições, espaços sociais, culturais e intelectuais que se irão organizar ou se reconfigurar.

\section{Educação a Distância: um desafio da atualidade}

A educação a distância, entre um número bastante considerável de docentes, ainda está no contexto da invenção de problemas (pensar) que se apresenta como dificuldade de manejo das novas tecnologias educacionais, fazendo surgir uma série de resistências no que tange à qualidade do processo de ensino/aprendizagem que pode ocorrer nas salas de aula on-line. Deixando um enorme caminho a ser percorrido, pela formação docente, para que a familiaridade com as novas tecnologias na educação permita as invenções e problematizações que poderão derivar de sua prática docente na medida em que sejam usuários cada vez mais competentes dessas TIC.

Novas concepções pedagógicas estão sendo elaboradas sob a influência da tecnologia educacional, com suas propostas de planejamento mais avançadas que concebem as tecnologias como fundamentos e técnicas de ensino, instrumentos a serviço do professor para a construção do conhecimento.

A fim de discutir essas questões, apresenta-se um estudo sobre como os professores percebem as diferenças entre o ensino na modalidade a distância, o que pensam a respeito do papel do professor e da possível qualidade dessa forma de ensinar de forma comparativa ao ensino presencial, modo de atuação ainda predominante na realidade da educação brasileira.

Nessa pesquisa, cujos aspectos estão relatados a seguir, foi feito um estudo exploratório sobre a percepção dos próprios docentes quanto às diferenças atribuídas por eles ao ensinar e aprender nas modalidades de ensino presencial e a distância. As entrevistas eram do tipo semi-aberto, com cinco perguntas centradas na referida temática, permitindo um estudo de caráter quanti-qualitativo.

Foram entrevistados 34 professores na totalidade, veremos a seguir seus posicionamentos para, logo a seguir, podermos discuti-los com base nessas reflexões que apresentamos até o momento.

Destes 34 professores, 16 são docentes do ensino superior, 8 do ensino médio e 10 do ensino fundamental. A primeira pergunta (Tabela 1) refere-se à visão de cada um deles sobre o que é mais determinante para que ocorra aprendizado, se estaria centrado no trabalho do professor apenas ou dependeria de outras variáveis.

Tabela 1

\begin{tabular}{|l|l|l|}
\hline $\begin{array}{l}\text { 1) Você acredita que } \\
\text { dependemos somente } \\
\text { dos professores para } \\
\text { aprender? }\end{array}$ & Não \\
\hline Ensino Fundamental & $90 \%$ & $10 \%$ \\
\hline Ensino Médio & $100 \%$ & $0 \%$ \\
\hline Ensino Superior & $94 \%$ & $6 \%$ \\
\hline
\end{tabular}

A grande maioria dos professores mostrou uma compreensão de que o aprender depende de diversas fontes de informação e de conhecimento, que ultrapassam a figura do professor. No gráfico abaixo (Figura 1) identificam-se as principais variáveis reconhecidas como primordiais, pelos professores, como coadjuvantes do aprendizado. 


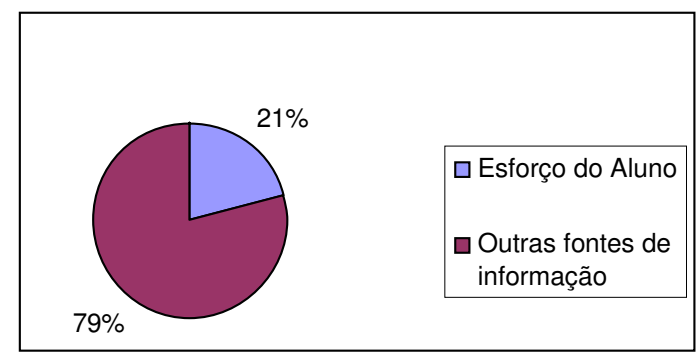

Figura 1

Este aspecto é muito relevante, uma vez que essa visão contribui para a descentralização do poder que tradicionalmente imperava nas relações do professor com seus alunos. Vê-se que existe uma aceitação bastante significativa por parte dos professores de que é importante que o aluno seja agente de seu processo de construção de conhecimento, embora se contate mais adiante que nem todos relacionam a EaD com uma modalidade que se apóia nessa concepção e inclusive pode permitir uma maior autonomia ao aluno durante o processo de ensino-aprendizagem.

Tabela 2

\begin{tabular}{|l|l|l|}
\hline $\begin{array}{l}\text { Você acredita que na } \\
\text { modalidade a distância o } \\
\text { aluno aprende igual ao ensino } \\
\text { presencial? }\end{array}$ & Não \\
\hline Ensino Fundamental & $40 \%$ & $60 \%$ \\
\hline Ensino Médio & $50 \%$ & $50 \%$ \\
\hline Ensino Superior & $25 \%$ & $75 \%$ \\
\hline
\end{tabular}

Percebe-se, conforme Tabela 2, que a maior parte dos professores acredita que não se aprende de modo exatamente igual no ensino a distância e no ensino presencial, no entanto ao justificar essa resposta (Figura 2) alguns apresentam argumentos que reforçam a idéia de que na $\mathrm{EaD}$ o aluno aprende mais, que há vantagens importantes em relação ao ensino presencial e outros acusam desvantagens em do ensino a distância em comparação com o ensino presencial. Faz-se necessário, portanto, o exame das razões apontadas pelos professores para justificar seu posicionamento frente a essa questão, pois este estudo nos permite verificar se os professores acreditam que uma modalidade de ensino possa ser ou não mais eficaz do que a outra e o porquê disto.

Nas respostas dos professores que dizem que não se dá um aprendizado de modo idêntico nas duas modalidades de ensino, vemos que os argumentos são predominantemente favoráveis e mais benéficos com relação ao ensino presencial, que aparece tendo maior aceitação entre os docentes. 


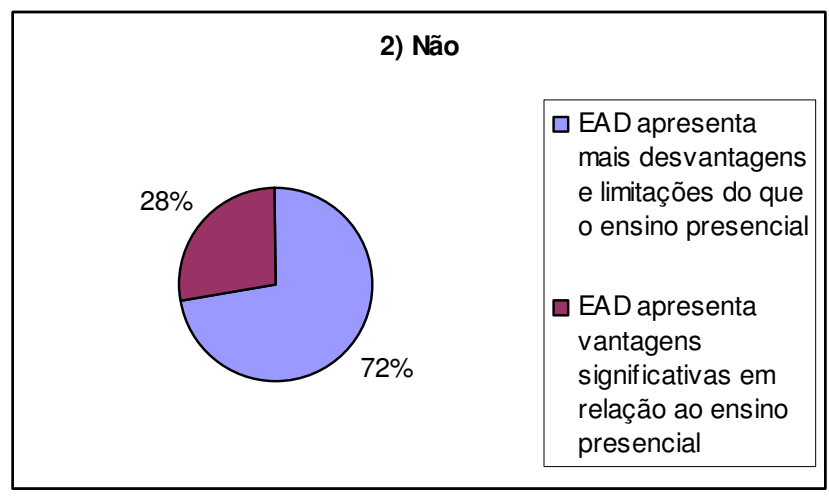

Figura 2

Com relação às limitações da $\mathrm{EaD}$, os professores ressaltam a importância da presença física do professor em sala de aula como uma suposta garantia ou facilitação da aprendizagem, sobretudo para que acompanhe o aluno e esteja junto dele para esclarecê-lo e assegurar-se de que ele não fique com dúvidas nos conteúdos estudados. Também valorizam o fato de que é importante conviver, que a interação social é parte do aprendizado e supostamente não estaria presente na modalidade a distância. Dentre estes argumentos predominantes, no ensino superior eles aparecem em menor número, apenas em 38\% das respostas. Já no ensino médio, 50\% dos professores apresentam esses argumentos e no ensino fundamental são $60 \%$. Pode-se constatar que os docentes do ensino superior pertencem ao segmento que apresenta maior aceitação ou reconhecimento de que a $\mathrm{EaD}$ pode representar um ensino de qualidade.

Quanto a essa valorização da interação social como um aspecto essencial para o aprendizado, vemos que a perspectiva teórica sócio-construtivista de educação fica bem representada por esse posicionamento dos professores, embora eles não estejam relacionando a $\mathrm{EaD}$ como uma modalidade que seja capaz de potencializar esse caráter interativo. Conforme Mehlecke e Guedes (2007) o ensino on-line cria possibilidades inúmeras de interação entre aluno/aluno e professor aluno, tanto por meio de ferramentas disponíveis nos ambientes virtuais de aprendizagem, quanto pelas estratégias metodológicas inovadoras que os professores adotam para incentivar um aprendizado cooperativo; esse aspecto é ressaltado por inúmeros autores, como por exemplo, Palloff e Pratt (2002) e Campos; Santoro; Borges; Santos (2003).

Um aspecto importante que corrobora para o entendimento dessa constatação é também a alta relevância que os docentes do ensino superior conferem à metodologia como fundamento para uma prática pedagógica capaz de atingir seus objetivos no que se refere à construção de conhecimentos que possa se realizar através do uso das novas tecnologias da informação e da comunicação. Essa preocupação com o aspecto metodológico e sua adequação à uma determinada modalidade de ensino também se apresenta entre os docentes do ensino médio.

Vejamos como os docentes que respondem que o ensino a distância pode oportunizar um aprendizado semelhante ao do ensino presencial defendem seu ponto de vista (Figura 3). Na sua maioria eles acreditam que boa parte do sucesso do aprendizado depende da metodologia que será adotada e outro aspecto ressaltado fio o envolvimento e o esforço do aluno, como fator definidor para que ele seja capaz de aprender. 


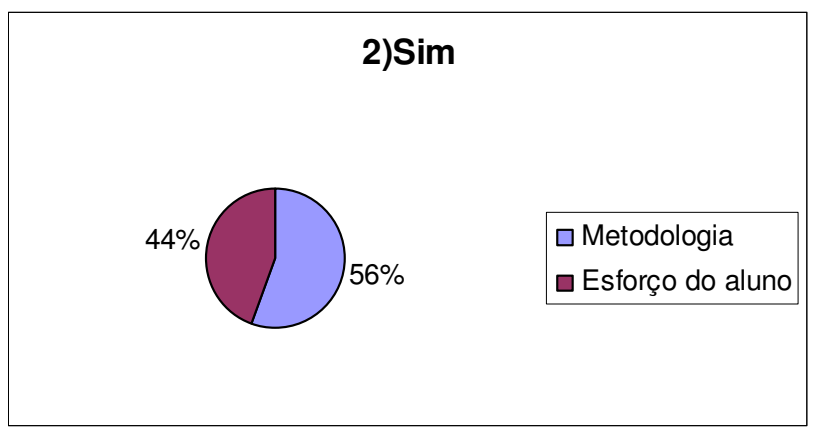

Figura 3

Na questão seguinte, interroga-se de modo mais direto a opinião dos professores sobre a metodologia que se deve utilizar em uma modalidade de ensino a distância ou em uma modalidade presencial. Deveria existir alguma mudança metodológica ou não?

Tabela 3

\begin{tabular}{|l|l|l|}
\hline $\begin{array}{l}\text { 3) Para ministrar aulas na } \\
\text { modalidade a distância o } \\
\text { professor precisa mudar a sua } \\
\text { metodologia? }\end{array}$ & Não \\
\hline Ensino Fundamental & $90 \%$ & $10 \%$ \\
\hline Ensino Médio & $87 \%$ & $13 \%$ \\
\hline Ensino Superior & $100 \%$ & $0 \%$ \\
\hline
\end{tabular}

Neste aspecto a grande maioria dos docentes (Tabela 3) acredita que a adequação metodológica implica transformações no fazer pedagógico de uma modalidade para a outra. No ensino superior todos foram unânimes ao responder a esta questão, mas nos demais segmentos a valorização de uma metodologia específica ao $\mathrm{EaD}$ foi significativamente predominante. Os argumentos apresentados referem-se à necessidade de que na EaD exista um planejamento específico para orientar os alunos durante o estudo, acompanhá-los, interagir com eles e cuidar para que exista de fato um aprendizado. Também destacaram a necessidade de um contato e de uma troca de informação entre professor e aluno que seja mais ágil e rápida nesse contexto e que aproveite os diversos canais de comunicação que essa modalidade de ensino oferece.

Seria interessante verificar se a interação que os docentes apontam como sendo algo que o professor precisa promover é a interação dele com cada aluno diretamente ou se os professores percebem a importância da interação entre os alunos em uma sala de aula virtual, ou até mesmo se imaginam que essa interação possa existir de fato e ser tão valiosa nessa modalidade de ensino.

Na próxima pergunta (Figura 4) os docentes são convidados a refletir sobre o papel do professor em cada uma dessas modalidades de ensino, ou seja, se elas demandam mudanças significativas na postura do professor ou não. 


\section{4) O papel do professor na educação a distância pode ser o mesmo do ensino presencial?}

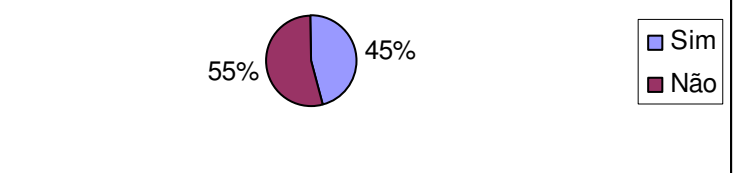

Figura 4

Tabela 4

\begin{tabular}{|c|c|c|c|}
\hline 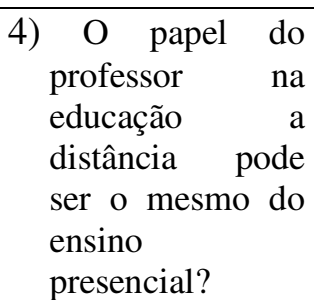 & Sim & Não & $\begin{array}{l}\text { Não } \\
\text { tem } \\
\text { opinião }\end{array}$ \\
\hline $\begin{array}{l}\text { Ensino } \\
\text { Fundamental }\end{array}$ & $50 \%$ & $50 \%$ & $0 \%$ \\
\hline Ensino Médio & $75 \%$ & $25 \%$ & $0 \%$ \\
\hline Ensino Superior & $50 \%$ & $44 \%$ & $6 \%$ \\
\hline
\end{tabular}

Conforme Tabela 4, vê-se que entre os entrevistados do ensino superior e do ensino fundamental predomina uma visão - nas respostas que afirmam que o papel do professor não muda de uma modalidade de ensino para a outra - que defende a idéia de que não importa em que modalidade, o professor sempre busca fazer com que seu aluno construa novos conhecimentos; nesse sentido, todas as modalidades de ensino somamse a este esforço pedagógico que está acima das diferentes metodologias a serem empregadas e das particularidades de cada contexto distinto que possa se apresentar nas relações de ensino-aprendizagem.

Um aspecto que merece ser sublinhado nasce nas respostas que justificam que o papel do professor na EaD é distinto. Dentre elas, $96 \%$ referem-se ao fato de que na $\mathrm{EaD}$ os professores acreditam que as exigências são distintas, que o professor nessa modalidade precisa esforçar-se para superar a distância e instaurar uma comunicação e um contato com seus alunos por meios diversos, que possibilitem o aprendizado. Também afirmam que nessa modalidade o professor precisa orientar seus alunos constantemente, uma vez que eles estarão fazendo de forma mais autônoma pesquisas e estudos com materiais muito variados. Alguns professores do ensino fundamental mencionaram que os materiais na $\mathrm{EaD}$ são mais ricos e que os alunos podem contar também com os tutores e receberem um acompanhamento mais individualizado.

Podemos refletir sobre essas considerações dos professores entrevistados como sendo reveladora de que, apesar de que muitos ainda acreditam que exista uma garantia ou segurança maior no ensino presencial porque o professor está fisicamente presente e isto facilitaria a interação e a comunicação com seus alunos, esta concepção pedagógica convive com uma paradoxal valorização e um evidente reconhecimento de que a EaD pode transformar a prática do professor e levá-lo a buscar modos de instaurar sua presença na virtualidade da sala de aula on-line. Além disso, sabe-se que há diversos caminhos que permitem ao professor de EaD fazer-se presente e facilitar aos alunos a 
prática da interação e do diálogo, de forma a torná-los mais responsáveis e atuantes na construção de seus saberes.

É possível perguntar se os professores, nessa última questão, não revelam, ou até mesmo chegam a confessar certa carência que sentem frente aos desafios que se colocam com a realidade das novas tecnologias na educação. Esse aspecto se reafirma na visão que eles apresentaram sobre o que seria para eles a educação on-line, a última questão colocada pelas entrevistas.

A grande maioria deles, em todos os segmentos de ensino, define educação online como o uso em si das TIC na educação, ou ainda uma educação que se dá virtualmente, a distância. Alguns professores do ensino fundamental comentam o fato de ser uma modalidade de ensino mais acessível para os estudantes e que responde às demandas da nossa sociedade na atualidade. Estes professores também valorizam o fato de que é uma modalidade de ensino que depende mais do interesse do aluno e do seu esforço para obter algum sucesso. Os professores do ensino médio apontam o baixo custo dessa modalidade de ensino e sua maior acessibilidade também, além da riqueza de recursos pedagógicos que ela oferece. Já os professores do ensino superior destacaram o fato de que é uma educação que exige maior participação do aluno no intento de concretizar seu aprendizado. Alguns docentes do ensino superior reconhecem que é uma modalidade de ensino que é mais trabalhosa para o professor e outros dizem que é uma educação unilateral que consiste na transmissão de conteúdo por parte do professor sem interação com o aluno. Constata-se a presença de perspectivas bastante diferentes no grupo de docentes sobre o que vem a ser a educação a distância e suas possibilidades diferenciadas de instaurar uma relação de ensino/aprendizagem.

\section{Considerações Finais}

Essa diversidade de concepções encontradas entre os docentes entrevistados, no que se refere à visão do ensino a distância e da configuração do ensinar e do aprender nessa modalidade, certamente reflete a realidade cada vez mais necessária de uma formação continuada para a docência, tanto para o uso das TIC no ensino presencial, e as reflexões e transformações metodológico-pedagógicas que daí surgirão, quanto para a atuação de professores na modalidade a distância. Existe um percurso de trocas de experiências, construção de competências e habilidades para que os professores possam sentir-se mais à vontade e atualizados diante desses desafios que se colocam; um percurso que está iniciado, certamente, mas que aponta muito ainda para fazer.

Pensar a EaD a partir das perspectivas teóricas educacionais que enfatizam a interação e a importância do conhecimento situado, conforme se discutiu nesse trabalho, torna-se uma realidade para os docentes na medida em que vivenciam na prática ações pedagógicas possíveis mediadas pelas TIC e se apropriam dessas experiências, incorporando esses conhecimentos de modo a transformar sua concepção frente à relação professor-aluno, formulando novas perguntas que se produzem frente à novidade e à aventura que representam para todos esses distintos papéis que o professor e o aluno podem desempenhar na modalidade de ensino a distância. Essa reconfiguração transforma o próprio professor ao trazer à tona novas dimensões do fazer pedagógico: o acoplamento tecnológico efetivamente depende dessa apropriação. Promover essa experiência, dentro da realidade de cada docente, é o desafio maior que uma proposta de formação de docentes em EaD enfrenta hoje. 


\section{Referências Bibliográficas}

CAMPOS, F.; SANTORO, F.; BORGES, M.; SANTOS, N. Cooperação e aprendizagem online. Rio de Janeiro: DP\&A, 2003.

FILATRO, A. As teorias pedagógicas fundamentais em EAD. In: LITTO, F. M.; FORMIGA, M. (orgs). Educação a distância: o estado da arte. São Paulo: Pearson Education do Brasil, 2009. (pp. 96-104).

KASTRUP, V. Novas tecnologias cognitivas: o obstáculo e a invenção. In: PELLANDA, N.: PELLANDA, E. (orgs.) Ciberespaço: um hipertexto com Pierre Lévy. Porto Alegre: Artes e Ofícios, 2000. (pp. 38-54)

MARASCHIN, C.; AXT, M. . Acoplamento tecnológico e cognição. In: VIGNERON, J.; OLIVEIRA, V. B. de. (org). Sala de aula e Tecnologias. São Bernardo do Campo: Universidade Metodista de São Paulo, pp. 39-51, 2005.

$<$ http://www.lelic.ufrgs.br/portal/images/stories/acoplamento\%20tecnologico\%20e\%20 cognicao.pdf>Acesso em: 22 fev. 2008.

MEHLECKE, Q; GUEDES, A. Estratégias para uma construção do gosto democrático: promovendo interações nas salas de aula on-line. In: CONGRESSO INTERNACIONAL DE EDUCAÇÃO A DISTÂACIA, 13º, 2007, Curitiba. Anais. Curitiba: Associação Brasileira de Educação a Distância.<http://www.abed.org.br/congresso2007/tc/55200732149PM.pdf>Acesso em: 31 out. 2008.

OLIVEIRA, E. G. Educação a Distância na transição paradigmática. Campinas: Papirus, 2003.

PALLOF, R.; PRATT, K. Construindo comunidades de aprendizagem no ciberespaço: estratégias eficientes para salas de aula on-line. Porto Alegre: ARTMED, 2002 . 